\title{
Vibration response of a railway track obtained using numerical models based on FEM.
}

\author{
A. Zougari, J. Martínez Miralles, S. Cardona Foix \\ Universitat Politècnica de Catalunya, Mechanical Engineering Department, Barcelona, Spain
}

\begin{abstract}
In the last forty years, researchers have developed models of wheel-rail contact force in order to study vibrations and rolling noise caused by railway traffic. These models range from analytical models, who consider a single rail of a railway track in contact with a rigid wheel attached to the bogie by means of the primary suspension, to numerical models based on finite element methods, boundary element, and mixed methods. Unlike analytical models, numerical models allow us to characterize more precisely the different components of railway track structure and consider the interaction between the entire track and a complete vehicle wheel-set. The study of the elements constituting the set of the railway track, the wheel-set and the primary suspension, as well as the knowledge of their influence in vibration generation and transmission due to train passage is of great interest when evaluating the possible vibration effects in the railway surrounding areas. This paper presents a numerical model of the track structure based on the finite element method. It is devoted to the study of the vibration response caused by vertical forces applied at any location on the rails. The numerical results are compared with analytical results previously presented in the bibliography.
\end{abstract}

\section{Introduction}

In recent years, the environmental impact arising from the construction and the operation of new railway tracks has assumed greater importance in the railway transportation development.

As for the railway operation, the environmental impact caused by the noise emission and vibration transmission to the surroundings is of great concern. This impact is especially significant in urban layouts, on surface, where the main problem is noise emission, and underground, where the vibration transmission creates more difficulties [1].

The main cause of vibrations when a train passes is the force fluctuations in the wheel-rail contact, resulting from wheel-rail profile irregularities.

The vibration generated depends on the vibration behaviour of the railway track, wheelset and primary suspension, and grows as the train speed, axle load, and especially the deteriorating state of the wheel profiles and rails increases. The worst deterioration occurs on the wheel tread, because it depends on traveled distance [2].

Several authors [3, 4] have focused on the study of vibrations generated in a railway track under the action of moving vehicles, and have presented different theories and analytical models. These models usually consist of a straight single rail railway: half-track contacting a wheel attached to the primary suspension of the bogie. Two basic models are used [4, 5, 6]: The first model assumes that the dynamic parameters of the track elements inertia, stiffness, and damping- are uniformly distributed along the track. This model is known as a distributed parameter model. The second model treats the track elements as individual elements and introduces the actual separation between these elements. The inertia, stiffness, and damping parameters are thus distributed discretely along the track. The second model is known as a discrete parameter model. Both models consider the rail as an Euler or Timoshenko beam. It is clear that these analytical models can not consider the possible interaction between rails. This interaction could be produced both through the railway track structure and through the wheel axis.

To analyze this interaction, the work presented proposes a numerical complete railway track model based on the finite element method, oriented to the characterization of the vibration generating mechanism.

This numerical model considers both rails of railway track structure.

The frequency response of the proposed numerical models is contrasted with the response provided by analytical models presented in previous publications [3, 4]. Finally, verification focuses on the existence of a significant interaction between rails.

The model has been developed using ANSYS 13 and has been applied to study a classical ballasted track with concrete sleepers. In both models the base of the track is considered rigid. 


\section{Numerical models of track}

The finite element method allows entering all the geometric parameters and materials involved or that are deemed necessary to solve the problem. For example, in the numerical models, the input parameters are divided in two parts. The first part refers to the rail properties: materials, elastic constants and damping factors. The second is the track geometric definition; distance between rails, distance between sleepers and the considered length of the railway track.

In the present paper two numerical models based on finite elements using the program ANSYS 13 have been developed. We pretend with the numerical models to characterize the dynamic response of a railway track by applying vertical excitation forces on the rails.

The first model represents only one single rail as it is based on the railway track symmetry in longitudinal direction. This model describes a classical ballasted halftrack.

The second numerical model is used to define a classical ballasted track. Therefore it allows us to study other aspects of railway track dynamic behavior which are not covered in the previous model, for example the interaction between rails through the sleepers and ballast.

The track components have been characterized using elements of ANSYS 13 library [7]. To select the elements, we considered the most relevant frequency range; where vibrations are generated by wheel-rail contact: 10 to $400 \mathrm{~Hz}$ [5].

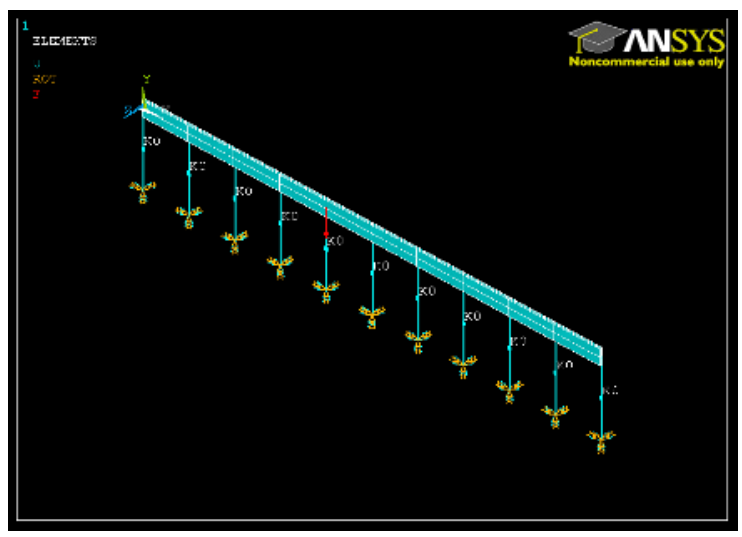

Fig. 1. Numerical model of classical ballasted half-track.

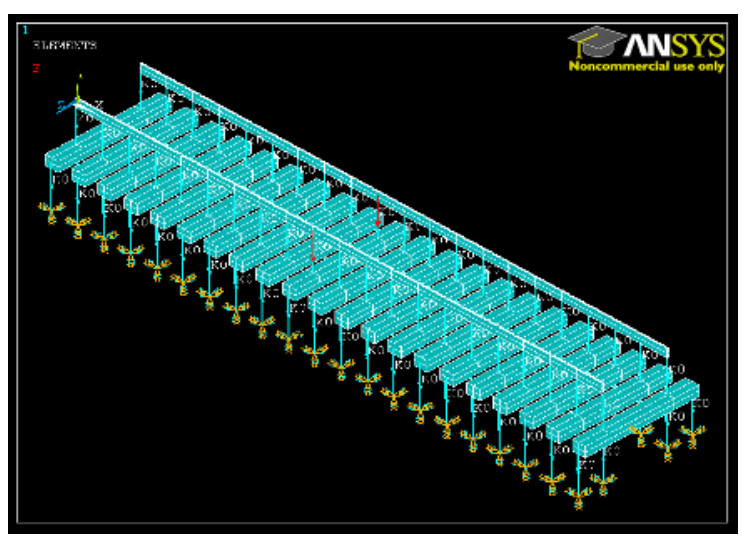

Fig. 2. Numerical model of classical ballasted track.
The figures 1 and 2 respectively show the representation in ANSYS of the classical ballasted halftrack and the classical ballasted track.

The analysis type used to characterize the railway behavior is the dynamic analysis. This analysis allows obtaining the temporal variation of displacements, stresses, strains and forces in a structure like a response to a loads combination that vary over time. In this analysis, the inertia and damping effects are fundamental. In the work presented, the loads are harmonic vertical forces of variable frequency, as it aims to get the frequency response of the track.

The results obtained with numerical models are compared below with the results obtained from analytical models developed in the literature.

Figure 3 shows a schematic classical ballasted halftrack model used in the comparison with numerical model results presented in the following section.

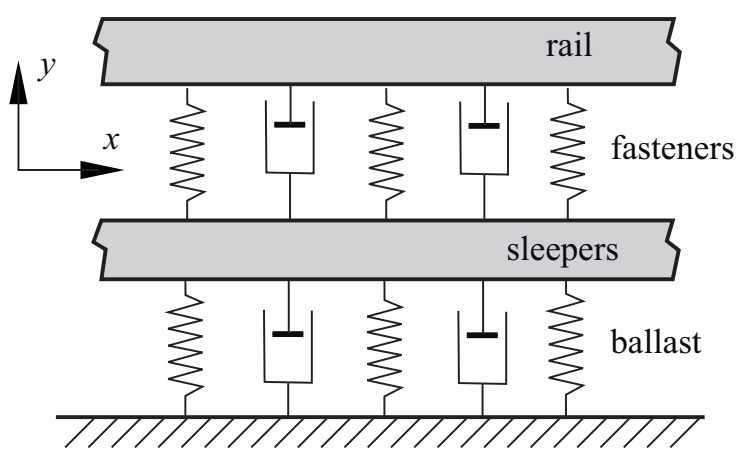

Fig. 3. Classical ballasted half-track model.

\section{Comparison between numerical and analytical models}

In order to validate the numerical models, the dynamic responses provided by the numerical models are compared with the response provided by the analytical model. The dynamic response is described in the frequency domain by means of the rail vertical receptance, a function that relates the vertical displacement of a point on the rail with a vertical harmonic force applied to the same point, or a different point, for each frequency $f$. The receptance is described by the following expression:

$$
\begin{aligned}
& R(f)=\frac{y_{\mathrm{c}}(f)}{F(f)} \\
& \text { with } \quad F(f)=F e^{j 2 \pi f t} \quad ; y_{\mathrm{c}}(f)=y_{\mathrm{c}} e^{j(2 \pi f t+\varphi)},
\end{aligned}
$$

$y_{\mathrm{c}}$ is the amplitude of the rail vertical displacement, $F$ the amplitude of vertical harmonic force applied to the rail and $\varphi$ the receptance phase.

The exciting harmonic force is applied to the rail just above a sleeper or a fixation. The parameters considered in the comparison are as shown in Table 1. 
Table 1. Parameters values of the used track.

\begin{tabular}{|c|c|}
\hline International rail gauge & $1,435 \mathrm{~m}$ \\
\hline Distance between sleepers & $0,6 \mathrm{~m}$ \\
\hline \multicolumn{2}{|l|}{ Track UIC 54} \\
\hline Mass of rail beam per unit length & $54,4 \mathrm{~kg} / \mathrm{m}$ \\
\hline Density of steel & $7850 \mathrm{~kg} / \mathrm{m}^{3}$ \\
\hline Young's modulus of steel & $210 \mathrm{GPa}$ \\
\hline Poisson's ratio of steel & 0,3 \\
\hline Rail cross-sectional area & $6,93 \cdot 10^{-3} \mathrm{~m}^{2}$ \\
\hline Rail second moment of inertia & $2,35 \cdot 10^{-5} \mathrm{~m}^{4}$ \\
\hline Loss factor of rail & 0,02 \\
\hline \multicolumn{2}{|c|}{ Conventional concrete mono-bloc ballasted track } \\
\hline Length of sleepers & $2,56 \mathrm{~m}$ \\
\hline Mass of sleepers & $324 \mathrm{~kg}$ \\
\hline Density of concrete & $1759 \mathrm{~kg} / \mathrm{m}^{3}$ \\
\hline Young's modulus of sleepers & $27,6 \mathrm{GPa}$ \\
\hline Poisson's ratio of sleepers & 0,175 \\
\hline Section of sleepers & $72 \cdot 10^{-3} \mathrm{~m}^{2}$ \\
\hline Sleeper moment of inertia & $34,6 \cdot 10^{-5} \mathrm{~m}^{4}$ \\
\hline Loss factor of sleepers & 0,1 \\
\hline Rail pad (fasteners) stiffness & $115,2 \mathrm{MN} / \mathrm{m}$ \\
\hline Rail pad(fasteners) loss factor & 0,2 \\
\hline Ballast stiffness & $13,74 \mathrm{MN} / \mathrm{m}$ \\
\hline Loss factor of ballast & 0,2 \\
\hline
\end{tabular}

Figure 4 presents the receptance magnitude comparison of the classical ballasted track at the point where the exciter harmonic force is applied, calculated with the analytical model and the numerical model. Both models representing the half railway track. The two models provide practically identical receptance around the range of interest, which confirms the equivalence of the numerical model with the analytical one.

The receptance shows two natural frequencies of the track at 42 and $328 \mathrm{~Hz}$. The first one corresponds to the vibration mode in which the set rail and sleepers tend to vibrate in phase. The second one corresponds to the vibration mode in which the rail and sleepers tend to vibrate in counter-phase. The characteristics of this second mode depend mainly on the stiffness and damping of elastic fixations between rail and sleepers.

Figure 5 shows the receptance comparison of the classical ballasted track, but this time using the full numerical model. In order to maintain the symmetry of the track vertical movement, the same harmonic force is applied in two points of both rails located on the same sleeper. This makes possible the comparison with the analytical half-track model, which considers implicit the symmetrical movement of both rails.

The first vibration mode coincides in frequency and amplitude for both models. In the second one, the natural frequency obtained with the full track model is slightly lower. This difference must be attributed to the consideration of the sleepers flexural rigidity, not covered in the analytical model nor the numerical half-track model, where the sleepers are treated as point masses.

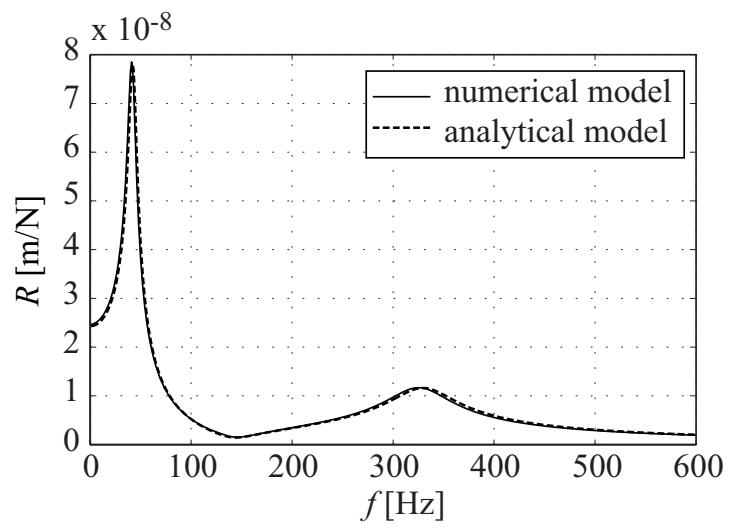

Fig. 4. Comparison of vertical receptance determined with the numerical and analytical models of the classical ballasted half-track.

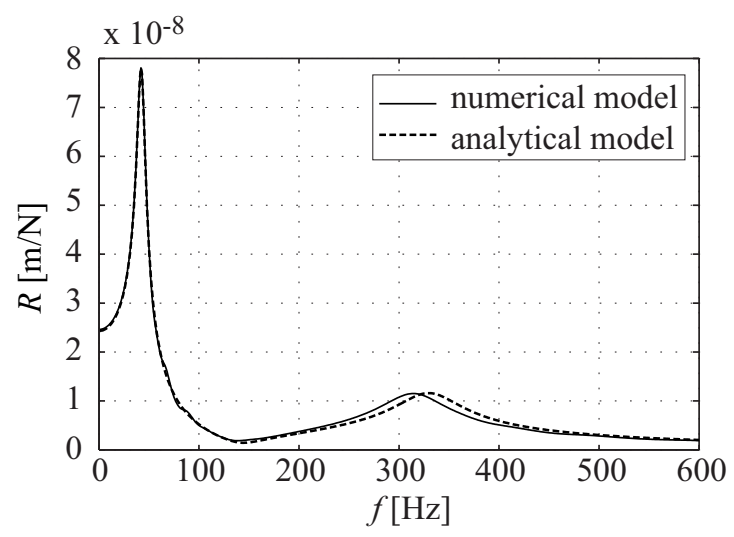

Fig. 5. Comparison of vertical receptance determined with the numerical model of the classical ballasted track and analytical model.

The numerical track model allows the comparison of receptances in both rails when the exciter force is applied only in one of the rails.

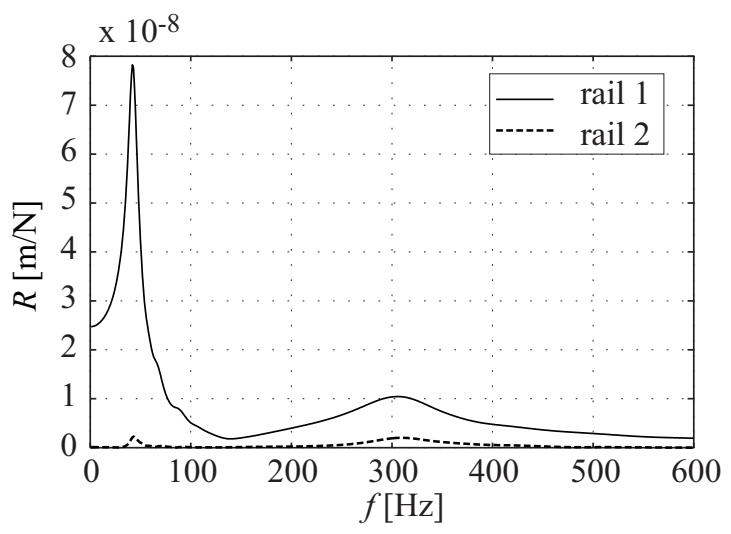

Fig. 6. Vertical receptance determined with the numerical model of the classical ballasted track; comparison of the receptances in the rail on which the force is applied -rail 1- and in the opposite rail - rail 2. 
Figure 6 shows the rail receptance on which it is applied the harmonic exciter force -rail 1- and the opposite rail -rail 2- obtained with the numerical classical ballasted track model. The point considered in both rails is located on the same sleeper.

The difference between the receptance amplitudes in both rails on the entire range of frequencies is evident. The attenuation of the vibration generated by the exciting force is important. We can therefore conclude that the interaction between rails is small.

This fact justifies the use of analytical models for half track. These models have been and still are employed by many researchers in the field of vibration generation and transmission caused by rail transport.

\section{Conclusions and future work}

The comparison of the track's receptance obtained with the numerical models and the receptance provided by the analytical model for the conventional track shows a very good agreement. This fact demonstrates that the used numerical models are trustworthy.

It is established that a numerical complete track model allows the study of aspects in the track vibratory behaviour, for example the relation between the vibration levels in different track locations, that other models cannot facilitate.

Using the numerical model for a classical complete track, with the described parameters, it has been proved that there is no significant interaction between both rails. Thus, the numerical model facilitates the analysis of the main factors that take part in the generation of vibrations due to the wheel-track contact, and its transmission to the surrounding areas.

It is intended to develop numerical models of the wheelset and primary suspension in order to analyze the vibration transmission between both rails through this set.

\section{References}

1. Department of Transportation. Federal Transit Administration, Transit noise and vibration impact assessment. USA, (2006).

2. J. Orta, J. Cardona, J. Romeu, A. Sánchez, "Influencia de la Rugosidad del carril en la generación de vibraciones en infraestructuras ferroviarias". In proceedings of the Congreso Acústica. Coimbra, Portugal, October (2008).

3. J. Otero, J. Martínez, M. A. de los Santos, "Evaluación de las vibraciones generadas al paso de un tren considerando diferentes tipologías de vía". In proceedings of the $9^{\text {th }}$ Congreso Iberoamericano de Ingeniería Mecánica. Las Palmas de Gran Canaria, Spain, 1403-1406, November (2009).

4. J. Otero, "Contribución al estudio de las vibraciones producidas por el contacto rueda-carril y su transmisión al entorno". PhD thesis. Mechanical Engineering Department, Universitat Politècnica de Catalunya, Barcelona, Spain, September (2009).
5. S. Iwnicki, Handbook of railway vehicle dynamics. Taylor and Francis Group. (2006)

6. J. Martínez, M.A. de los Santos, S. Cardona, $A$ convolution method to determine the dynamic response in a railway track submitted to a moving vertical excitation. Machine Vibration 4, 142-146, (1995).

7. Ansys Release13 Multiphysics, Ansys Release13 Documentation. Ansys Inc, (2011).

8. T. X. Wu, D.J. Thompson, A hybrid model for the noise generation due to railway wheel flats. Journal of Sound and Vibration, 251(1), 115-139, (2002).

9. Nielsen, J.C.O., C.R. Fredo, Multi-disciplinary optimization of railway wheels. Journal of Sound and Vibration, 293, 510-521, (2006). 